\title{
MENGIDENTIFIKASI PANDANGAN NATURE OF SCIENCE (VNOS) CALON GURU KIMIA
}

\section{IDENTIFICATION THE VIEWS OF NATURE OF SCIENCE (VNOS) FROM THE PRE-SERVICE CHEMISTRY TEACHER}

\author{
Inelda Yulita ${ }^{1, *}$, Nina Adriani ${ }^{1}$, Amin Fatoni ${ }^{2}$, Dadan Hermawan², Ahmad Mudzakir ${ }^{3}$ \\ ${ }^{1}$ Universitas Maritim Raja Ali Haji \\ Jalan Raya Dompak, Tanjungpinang, Kepulauan Riau 29111 \\ ${ }^{2}$ Universitas Jenderal Soedirman \\ Jl. Profesor Dr. HR Boenyamin No. 708, Banyumas, Jawa Tengah 53122 \\ ${ }^{3}$ Universitas Pendidikan Indonesia \\ Jl. Dr. Setiabudi No. 299, Bandung, Jawa Barat 40154 \\ *e-mail korespondensi: inelda_chem@umrah.ac.id
}

\begin{abstract}
Abstrak
Sangat penting untuk mengetahui pandangan calon guru kimia tentang Nature of Science karena akan mempengaruhi kinerja disaat menjadi guru yang sesungguhnya. Guru yang memiliki pandangan mengenai nature of science (VNOS) yang benar, akan mentransfer kemampuan tersebut kepada para siswanya, begitu juga sebaliknya pemahaman yang salah juga akan tertularkan kepada para siswa. Aspek VNOS yang akan dibahas meliputi (1) Tentativeness, (2) Empirical basis, (3)Subjectivity, (4) Creativity, (5) Social/cultural embeddedness, dan (6) Theories and laws. Metode yang digunakan dalam penelitian ini adalah deskriptif. Instrumen yang digunakan dalam penelitian ini adalah kuisioner VNOS form B yang telah diadopsi dari Lederman dan pedoman wawancara. Pandangan calon guru kimia dijelaskan dan dikategorikan sebagai naïve, eclectic, dan informed untuk setiap aspek NOS. Hasil penelitian menunjukkan bahwa calon guru kimia memiliki pandangan yang cukup memadai tentang Nature of Science.
\end{abstract}

Kata kunci: calon guru kimia, Nature of science, VNOS.

\begin{abstract}
It is important to understand the views of pre-service chemistry teachers about the Nature of Science, since it will affect one's performance as one become the real teacher. Teachers who have a view of the Nature of Science (VNOS) will transfer these abilities to their students, as well as contradicting the incorrect understanding which will also be transmitted to the students. There are 6 aspects of VNOS that will be discussed in this research: 1.Tentativeness, 2.Empirical basic, 3.Subjectivity, 4.Creativity, 5.Social/cultural embeddedness, and 6.Theory and law. The method used in this research was descriptive. The data were gathered through a VNOS questionnaire form B which had been adopted from Lederman and interview guidelines. The view of pre-service chemistry teachers are discussed and categorized as naïve, eclectic and informed for every aspect of VNOS. The result showed that preservice chemistry teachers had sufficient knowledge about Natural of Science.
\end{abstract}

Keywords: pre-service chemistry teacher, Nature of Science, VNOS 


\section{PENDAHULUAN}

Nature of Science (NOS) didefinisikan sebagai hakekat pengetahuan yang melibatkan aspek filosofi, sosiologi, dan historis suatu pengetahuan. NOS adalah bagian sains yang harus dipahami oleh seorang calon guru. Hal ini dikarenakan pemahaman guru merupakan pengetahuan yang akan diterima oleh siswa. Namun, hal ini sering terabaikan atau tidak mendapat perhatian yang baik (William $\mathrm{F}$ McComas \& Almazroa, 1998). Padahal NOS memberikan latar belakang yang penting bagi siswa pada saat pembelajaran, yaitu tentang bagaimana sains dan ilmuwan bekerja dan bagaimana pengetahuan ilmiah tercipta, divalidasi, dan dipengaruhi (W F McComas, 2002).

Dalam pembelajaran, agar siswa dapat memahami Nature of Science dengan benar, maka guru harus terlebih dahulu memiliki pandangan yang tepat dan baik terhadap NOS, salah satunya dengan kemampuan mendesain pembelajaran yang mampu meningkatkan literasi sains siswa (Asikin \& Yulita, 2019). Pembelajaran kimia merupakan bagian dari sains yang tidak boleh lepas dari hakekat sains (nature of science) yang menuntut pembahasan tentang persoalan ilmiah (Nentwig \& Demuth, 2007). Pemahaman tentang nature of science (NOS) sangat penting dalam pembelajaran, karena dapat meningkatkan kemampuan literasi sains siswa (V. L. Akerson, Abd-el-khalick, \& Lederman, 2000). Selain itu, pemahaman mengenai NOS dapat meningkatkan metakognisi siswa dalam pembelajaran (Abd-el-khalick \& Akerson, 2009).

Lederman et.al., (2002) menegaskan bahwa NOS merupakan bagian yang berkenaan dengan pemahaman mengenai hakikat sains ilmiah secara utuh. Pemahaman ini meliputi sifat empiris ilmu pengetahuan, sifat kreatif dan imaginatif, menanamkan sosial dan budaya, dan sifat tentatif. Siswa yang tidak memahami hakikat sains hanya memiliki kesadaran akan adanya hubungan ilmu pengetahuan sains dengan konteks kehidupan di sekitarnya, tanpa mampu memberikan penjelasana mengada dan bagaimana (Yulita, 2018). Menurut McComas (2002) menyatakan bahwa integrasi NOS di dalam pendidikan bukan untuk mendoktrinasi, tetapi untuk menunjukkan alasan untuk menerima suatu keadaan tertentu.

Terdapat enam aspek nature of science (NOS) (Lederman et al., 2002). Aspek pertama adalah Empiris Base yang bermakna bahwa pengetahuan ilmiah didasarkan pada data/bukti yang didapat dari observasi dengan panca indera dan/atau percobaan. Aspek kedua adalah tentativeness yang maksudnya pengetahuan ilmiah bukanlah sesuatu yang mutlak kebenarannya dan tanpa kesalahan., namun dapat berubah atau disempurnakan dengan bukti pengamatan baru.

Aspek ketiga adalah theories and law, dapat diartikan bahwa pengetahuan ilmiah dapat berupa hukum atau dapat juga berupa teori. Antara hukum dan teori memiliki kedudukan yang sama dan tersendiri di dalam sains. Aspek ke empat adalah socio/cultural embeddednes yang bermaksud bahwa ilmu pengetahuan adalah hasil usaha manusia, yang akan dipengaruhi oleh masyarakat dan budaya di mana ia dipraktekkan. Sistem nilai dan budaya akan mempengaruhi apa dan bagaimana ilmu pengetahuan dilakukan, ditafsirkan, dan diterima. Aspek ke lima adalah creativity yang maksudnya bahwa pengetahuan ilmiah tercipta dari imajinasi manusia, kreativitas dan penalaran logis. Pengetahuan ilmiah dapat berkembang dikarenakan kreativitas. Aspek ke enam adalah subjective, yang bermaksud bahwa subyektivitas seorang ilmuwan tidak dapat terhindarkan dalam ilmu pengetahuan. Kepribadian, kepercayaan, agenda diri, dan pengalaman akan mempengaruhi apa dan bagaimana seorang ilmuwan melakukan pekerjaannya.

\section{METODE PENELITIAN}

Metode yang digunakan pada penelitian ini adalah deskriptif. Penelitian ini merupakan penelitian kualitatif yang bertujuan untuk mengungkapkan fakta, keadaan, atau fenomena yang terjadi saat penelitian berlangsung. Menurut Sugiyono (2012), metode deskriptif adalah suatu metode yang digunakan untuk menggambarkan atau menganalisis suatu hasil penelitian tetapi tidak digunakan untuk membuat kesimpulan yang lebih luas. Tujuan dari penelitian deskriptif kualitatif ini akan menjadi pedoman bagi peneliti untuk melakukan penelitian berikutnya.

Instrumen yang digunakan dalam penelitian ini adalah kuesioner yang dikembangkan oleh Lederman (2002) yaitu kuesioner VNOS-B yang sudah valid. Peneliti mengadopsi seutuhnya kuesioner tersebut dengan melanjutkan validasi terjemahan oleh expert bahasa Inggris. Selain itu, instrumen yang digunakan adalah pedoman wawancara dengan menggunakan pertanyaan yang ada pada 
kuesioner VNOS Form B. Item kuesioner yang terdiri dari 6 aspek VNOS yaitu : (1)

Tentativeness, (2) Empirical basis, (3)

Subjectivity, (4) Creativity, (5) Social/cultural embeddedness, dan (6) theories and laws.

Pada penelitian ini, subjek penelitian adalah calon guru kimia (pre-service chemistry teacher) diambil dari mahasiswa Universitas Maritim Raja Ali Haji yang berada disemester 8 sebanyak 30 orang. Untuk subjek wawancara diambil secara non random purposive sampling. Dimana subjek yang diwawancarai dipilih berdasarkan tujuan dan pertimbangan tertentu dari peneliti.

Data penelitian dianalisis dengan mengelompokkan jawaban kuesioner dan wawancara ke dalam 3 kategori (Ağlarc1, Sarıçayır, \& Şahin, 2016) yaitu : naïve, eclectic, dan informed. Dimasukkan ke dalam kategori naïve apabila pandangan mahasiswa calon guru kimia menyimpang dari konsep NOS sebenarnya. Kategori eclectic jika pandangan mereka sesuai dengan konsep NOS sebenarnya tapi tidak mampu menjelaskan atau menyebutkan contohnya. Berikutnya, kategori informed dimasukkan apabila pandangannya sesuai dengan konsep NOS sebenarnya dan mampu menjelaskannya secara tepat. Kategorikategori tersebut akan diberikan poin-poin berikut, yaitu : nä̈ve $(\mathrm{N})=0$, eclectic $(\mathrm{E})=1$, dan informed $(\mathrm{F})=2$. Selanjutnya, jumlah jawaban responden akan dipersentasikan dengan cara membandingkan jumlah jawaban yang kategori sama dengan jumlah item jawaban seluruhnya $(X=180)$

\section{HASIL DAN PEMBAHASAN}

Penelitian ini mengumpulkan data dengan mengadopsi instrumen penelitian kuisioner yang telah valid dan reliabel dari Lederman et al (2002). Pada penelitian ini dilakukan validasi terjemahan agar bahasa yang digunakan pada kuisioner tersebut benar dan tepat. Adapun indikator validasi tersebut terdiri dari 4 aspek, yaitu 1) ketepatan hasil terjemahan, 2) kesesuaian makna dengan kuesioner asli, 3) menggunakan EYD yang tepat, dan 4) Hasil terjemahan dapat dipahami pembaca. Validasi dilakukan oleh 3 orang ahli bahasa dengan hasil CVR 0,98 kategori sangat valid. Selanjutnya, jawaban untuk setiap pertanyaan kuisioner tersebut didapatkan dengan melakukan Forum Group Discussion (FGD) bersama 5 orang ahli dalam bidang kimia dan NOS. Hasil FGD dijadikan standar dalam mengolah data hasil jawaban responden.

Sebanyak 30 orang responden mengisi kuesioner tersebut. Responden merupakan calon guru kimia yang diambil dari mahasiswa semester 8. Seluruh responden dalam masa meyelesaikan tugas akhir, dimana mereka telah menempuh semua mata kuliah, baik mata kuliah kimia maupun pedagogi. Selain itu mereka juga telah selesai melakukan Praktek Pengalaman Lapangan (PPL) di sekolah. Sehingga, dianggap bahwa mereka adalah calon guru kimia.

Setelah mengumpulkan kuesioner VNOS form $B$, selanjutnya dilakukan analisis jawaban dengan mengelompokkan ke dalam 3 kategori, yaitu naïve, eclectic, dan informed. Untuk menjaga kevalidan analisis jawaban kuesioner tersebut, maka peneliti bersama pembantu peneliti melakukan diskusi untuk membuat suatu kesepakatan mengenai kategori jawaban yang diberikan responden. Apabila antara analisator berbeda pendapat antara satu dengan yang lainnya, maka dilakukan diskusi hingga didapatkan satu kesepakatan. Hasil kesepakatan atas pengkategorian jawaban calon guru kimia terhadap NOS, dapat dilihat pada tabel 1.

Tabel 1. Kategori jawaban calon guru kimia pada kuesioner VNOS Form B $(\mathrm{N}=30)$

\begin{tabular}{lllllllll}
\hline \multirow{2}{*}{ No } & Calon & \multicolumn{6}{c}{ Item $_{\text {Kuesioner }}{ }^{\mathrm{a}}$} & \multirow{2}{*}{ Skor $^{\mathrm{b}}$} \\
\cline { 3 - 7 } & guru kimi & 1 & 2 & 3 & 4 & 5 & 6 & \\
\hline 1 & RHM & F & F & E & F & F & N & 9 \\
2 & HYN & F & E & E & N & E & E & 6 \\
3 & TNA & N & F & E & N & N & N & 3 \\
4 & MIK & N & F & E & E & E & E & 6 \\
5 & RSM & N & F & E & F & F & E & 8 \\
6 & FJ & N & F & E & E & E & E & 6 \\
7 & HSM & N & E & F & N & N & N & 3 \\
8 & MRS & F & F & F & E & F & F & 11 \\
9 & SFT & E & F & N & E & E & E & 6 \\
10 & JSK & F & E & F & E & E & F & 9 \\
11 & LCS & F & F & F & F & F & E & 11 \\
12 & RHT & F & F & F & F & F & E & 11 \\
13 & MDN & F & F & F & F & F & E & 11 \\
14 & SRN & F & F & F & F & F & E & 11 \\
15 & IMM & E & F & N & N & E & N & 4 \\
16 & STR & F & E & E & F & F & F & 10 \\
17 & NRL & N & F & E & F & F & F & 9 \\
18 & OVR & F & F & E & E & E & N & 7 \\
19 & DHS & F & F & F & F & F & E & 11 \\
20 & VBO & E & E & F & F & F & E & 9 \\
21 & APL & E & E & E & F & F & E & 8 \\
22 & YLN & E & E & E & E & E & E & 6 \\
23 & ZSA & N & E & E & N & E & N & 3 \\
24 & DBY & E & E & F & F & F & E & 9 \\
25 & MGW & N & E & N & F & F & E & 6 \\
26 & DSM & N & E & E & F & F & E & 7 \\
\hline
\end{tabular}




\begin{tabular}{lllllllll}
\hline \multirow{2}{*}{ No } & Calon & \multicolumn{9}{c}{ Item Kuesioner $^{\mathrm{a}}$} & \multirow{2}{*}{ gkor $^{\mathrm{b}}$} \\
\cline { 3 - 8 } & guru kimia & 1 & 2 & 3 & 4 & 5 & 6 & \\
\hline 27 & PYL & N & F & E & N & E & N & 4 \\
28 & CCI & N & E & F & F & F & N & 7 \\
29 & FZZ & E & E & N & N & F & E & 5 \\
30 & DAS & F & F & F & F & F & E & 11 \\
& \multicolumn{6}{c}{ X $^{\mathrm{c}}=180$} \\
\hline
\end{tabular}

a. Item pada kuesioner VNOS form $\mathrm{B}$ (lampiran $\mathrm{A}$ )

b. $\quad S k o r N=0, E=1$ dan $F=2$

c. $\mathrm{X}$ adalah jumlah item jawaban seluruh responden $=30$ responden $\mathrm{x} 6$ item $=180$.

Dari tabel 1 dapat dilihat sebaran jawaban 30 orang calon guru kimia dalam kategori naïve, eclectic, dan informed. Jika dilihat dari jumlah item jawaban seluruh responden (X), maka terdapat kategori jawaban informed sejumlah 79 buah $(X=180,44 \%)$, eclectic sejumlah 69 buah $(\mathrm{X}=180,38 \%)$, dan nä̈ve sejumlah 32 buah $(\mathrm{X}=180,18 \%)$. Jika kategori eclectic dan informed adalah kategori jawaban yang memiliki pandangan yang telah sesuai dengan NOS, maka hasil kuisioner menunjukkan bahwa calon guru kimia memiliki pandangan NOS yang cukup memadai. Hal ini seiring dengan hasil penelitian Akerson dan Donnelly, (2009) yang menyatakan bahwa pandangan siswa terhadap aspek-aspek NOS sudah mengalami perkembangan yang cukup memadai.

Dari data di atas hanya $44 \%$ dari calon guru kimia tersebut yang dapat memberikan penjelasan atau contoh. Selanjutnya jumlah yang lebih sedikit yaitu $18 \%$ kategori naïve, dimana calon guru kimia tidak memiliki pandangan yang tepat terhadap NOS. Hal ini membuka peluang bahwa pandangan terhadap NOS masih bisa ditingkatkan. Hal ini seiring dengan integrasi NOS ke dalam kurikulum, bahan ajar, atau desain pembelajaran. Peluang ini akan membantu tugas pokok mereka nanti di saat menjadi guru (McComas, 2002 ; Holbrook, 2005)).

Selanjutnya, jika dilihat dari skor yang di dapat, calon guru kimia yang mampu menjawab 5 item atau lebih (skor $\geq 10$ ), ada sebanyak 7 orang $(\mathrm{N}=30,23 \%)$ dengan kategori hanya 1 item yang nä̈ve atau eclectic, namun selebihnya sudah masuk kategori informed. Sedangkan yang hanya mampu menjawab 2 item atau kurang (skor $\leq 4)$, ada sebanyak 5 orang $(\mathrm{N}=30$, $17 \%$ ) dengan maksimal hanya 1 item yang masuk pada kategori jawaban informed, selainnya adalah eclectic dan naïve. Hal ini berarti bahwa $60 \%$ calon guru kimia yang tidak masuk dalam range tersebut memiliki variasi kategori jawaban antara informed, eclectic dan naïve. Hal ini menunjukkan bahwa banyak calon guru kimia yang memiliki pandangan NOS berada diantara informed dan naïve. Dapat dikatakan juga bahwa calon guru kimia rata-rata sudah memiliki pandangan NOS yang sesuai, namun belum mampu memberikan contoh atau penjelasan yang lebih lengkap dan tepat.

\section{Kategori informed}

Ada beragam jawaban calon guru kimia yang menggambarkan pandangan yang tepat beserta penjelasannya mengenai nature of science (NOS). Hal ini dapat dilihat dari beberapa jawaban berikut :

Ya, teori dapat berubah. Teori dapat berubah dari waktu ke waktu mengikuti perkembangan zaman dan teknologi. Teori dapat diperbaiki atau dimodifikasi karena semakin banyaknya eksperimen yang dilakukan (LCS, Q1)

Ya, pernah berubah dan mengalami perkembangan. Karena teori yang muncul pertama kali ialah teori yag disimpulkan dari hasil percobaan/ eksperimen dengan bantuan teknologi yang tersedia di zaman itu. Semakin maju zaman, muncul teknologi yang lebih canggih. Maka percobaan akan menghasilkan teori-teori baru yang akan menyempurnakan teori-teori lama. (HYN, Q1)

Teori bisa berubah. Teori disusun berdasarkan penjelasan yang berbasis bukti eksperimen. Contohnya teori atom Dalton yang menyatakan bahwa atom hanya seperti bola pejal, namun teori tersebut tergantikan oleh teori atom Thomson dimana Thomson melakukan eksperimen dan menemukan partikel baru yang namanya elektron. Sehingga gugurlah teori atom Dalton dan tergantikan dengan teori atom Thomson. Begitu seterusnya dengan Rutherford, Bohr dan teori atom modern. (OVR, Q1)

Pernyataan di atas merupakan jawaban kategori informed atas pertanyaan kuisioner yang pertama. Adapun pertanyaannya meminta pandangan responden terhadap suatu teori, apakah teori bisa berubah atau bersifat tetap. Dari jawaban kategori informed, calon guru kimia mampu menjawab pertanyaan tersebut dengan pandangan NOS yang tepat, dimana teori dapat berubah seiring dengan adanya eksperimen-eksperimen baru dan penggunaan teknologi yang lebih maju. Calon guru kimia juga mampu menyebutkan contoh yang dapat memperkuat pernyataan tersebut seperti perkembangan model atom dari Dalton hingga model atom modern. 


\section{Kategori Eclectic}

Beberapa jawaban calon guru kimia yang masuk pada kategori eclectic, dimana mereka telah memiliki pandangan NOS yang tepat, namun belum bisa memberikan penjelasan atas jawabannya. Adapun gambaran jawaban tersebut, adalah sebagai berikut :

Teori ilmiah itu masih dalam bentuk spekulasi yang membutuhkan penelitian lanjutan untuk membenarkan teori tersebut. Sedangkan hukum ilmiah merupakan pernyataan yang telah dibuktikan kebenarannya dengan eksperimen (STR, Q3)

Hukum ilmiah merupakan suatu bagian dari ilmu pengetahuan yang dapat menjelaskan suatu peristiwa. Contoh hukum kekekalan energi. Sedangkan teori ilmiah merupakan pandangan umum yang sulit dibuktikan secara langsung. Contohnya teori charles darwin. (APL, Q3)

Jawaban di atas merupakan jawaban kategori eclectic untuk pertanyaan kuisioner yang ketiga. Adapun pertanyaan meminta pandangan responden terhadap perbedaan antara teori ilmiah dengan hukum ilmiah beserta contoh yang dapat mengilustrasikan hal tersebut. Dari gambaran jawaban di atas terlihat bahwa responden telah menjawab dengan tepat bahwa terdapat perbedaan antara teori ilmiah dengan hukum ilmiah, namun belum mampu memberikan contohnya. Adapun bagi responden yang memberikan contoh, tapi tidak mampu mengilustrasikan contoh tersebut agar dapat memperkuat penjelasannya.

\section{Kategori Nä̈ve}

Jawaban kuesioner yang masuk pada kategori nä̈ve menunjukkan bahwa responden belum memiliki pandangan yang tepat mengenai NOS atau bahkan memiliki pandangan yang salah. Berikut gambaran jawaban nä̈ve yang diberikan adalah sebagai berikut :

Teori tidak pernah berubah dari dahulu hingga sekarang, karena Tuhan telah menetapkan sesuatu yang permanen di dalam kehidupan. Seperti hari-hari kita tetap melihat adanya siang dan malam yang selalu tetap. (Q1, TNA)

Saya tidak sepakat kalau astronom yang melihat eksperimen dan data yang sama akan memiliki kesimpulan yang berbeda. Menurut saya jika semua data sama pasti hasilnya satu pendapat dan pandangan, karena itu sudah ada bukti. (Q6, ZSA)

Seorang ilmuwan dalam melakukan percobaan hanya melakukan proses eksperimen saja. Sedangkan kreatifitas hanya dimiliki oleh para seniman, bukan ilmuwan (Q5, HSM)
Jawaban di atas termasuk pada kategori jawaban nä̈ve dimana jawaban tersebut tidak sesuai dengan pandangan NOS. Jawaban pada item kuesioner nomor 1 TNA menyatakan pandangan bahwa teori tidak pernah berubah dan akan selalu tetap sampai kapan pun. Berdasarkan hasil wawancara dengan TNA, didapatkan pandangan bahwa teori atom yang masih dipelajari sampai sekarang bermakna bahwa teori tersebut masih berlaku dan bersifat tetap.

Selanjutnya pandangan ZSA terhadap item kuisioner nomor 6 adalah tidak sepakat mengenai adanya perbedaan pendapat astronom mengenai alam semesta jika eksperimen dan data yang dilihat sama. Menurutnya jika eksperimen dan data yang dilihat sama, maka kesimpulan juga harus sama. Berikutnya pandangan HSM pada item kuesioner nomor 5 yang menyatakan bahwa kreativitas bukan bidang seorang ilmuwan, melainkan bidang seorang seniman. Pandangan yang tidak tepat mengenai ilmuwan hanya melakukan percobaan atau eksperimen lalu membuat kesimpulan, masih dipahami oleh beberapa calon guru kimia sebagai sesuatu yang benar. Padahal ilmuwan tidak dapat berkreasi membuat suatu rangkaian percobaan atau pengamatan tanpa imajinasi. Oleh karena itu, kreativitas dan imajinasi sangat penting dalam sains (Lederman et al., 2002).

Berikut, distribusi jawaban calon guru kimia terhadap pandangan terhadap Nature of Science (NOS) yang dikelompokkan sesuai aspek NOSnya. Setiap item pada kuisioner mewakili pandangan NOS pada aspek yang berbeda. Enam item pada kuisioner mewakili enam aspek NOS, yaitu tentativeness, empirical basis, theories and laws, creativity, social/ cultural embeddedness, dan subjectivity. Distribusi jawaban akan dibagi menjadi naüve, eclectic, dan informed. Hasil distribusi dapat dilihat pada tabel 2 .

Tabel 2. Distribusi jawaban calon guru kimia berdasarkan kriteria dan klasifikasi

\begin{tabular}{lllll}
\hline \multirow{2}{*}{ No } & \multirow{2}{*}{ Item } & \multicolumn{3}{c}{ Kategori } \\
\cline { 2 - 5 } & Naïve & Eclectic & Informed \\
\hline 1 & Tentativeness & $11(37 \%)$ & $7(23 \%)$ & $\mathbf{1 2 ( 4 0 \% )}$ \\
2 & Empirical basis & $0(0 \%)$ & $13(43 \%)$ & $\mathbf{1 7 ( 5 7 \% )}$ \\
3 & Theories \& laws & $4(13 \%)$ & $\mathbf{1 4 ( 4 7 \% )}$ & $12(40 \%)$ \\
4 & Creativity & $7(23 \%)$ & $7(23 \%)$ & $\mathbf{1 6 ( 5 4 \% )}$ \\
5 & Creativity & $2(7 \%)$ & $10(33 \%)$ & $\mathbf{1 8 ( 6 0 \% )}$ \\
6 & Subjectivity, dan 8(27\%) & $\mathbf{1 8 ( 6 0 \% )}$ & $4(13 \%)$ \\
\multicolumn{2}{l|}{$\begin{array}{l}\text { Social/ cultural } \\
\text { embeddedness }\end{array}$} & & \\
\hline
\end{tabular}


Berdasarkan tabel 2, dapat dilihat bahwa dari 6 aspek NOS, 4 aspek diantaranya didominasi oleh jawaban kategori informed. Sedangkan 2 aspek lainnya didominasi jawaban kategori eclectic. Dan tidak ada kategori jawaban yang didominasi oleh kategori naïve. Dari kondisi ini terlihat bahwa pandangan calon guru kimia tidak sepenuhnya buruk, melainkan cukup baik. Bahkan pada aspek empirical basis tidak ada pandangan yang salah terhadap NOS, karena kategori jawaban nä̈ve adalah $0 \%$.

Kategori jawaban mengenai VNOS calon guru kimia ini akan diuraikan satu persatu, sebagai berikut :

\section{Aspek Tentativeness}

Pertanyaan pertama pada kuisioner dapat menggambarkan pandangan para calon guru kimia terhadap aspek tentativeness. Aspek tentativeness menunjukkan bahwa pengetahuan ilmiah, meskipun dapat diandalkan dan tahan lama, namun tidak pernah absolut atau pasti (Lederman et al., 2002). Pertanyaan kuisioner yang pertama mengenai teori yang dihasilkan oleh ilmuwan pernah berubah atau tidak, seperti teori atom, teori molekul kinetik, teori sel, dan lainnya. Masing-masing pendapat responden dimintakan penjelasaannya.

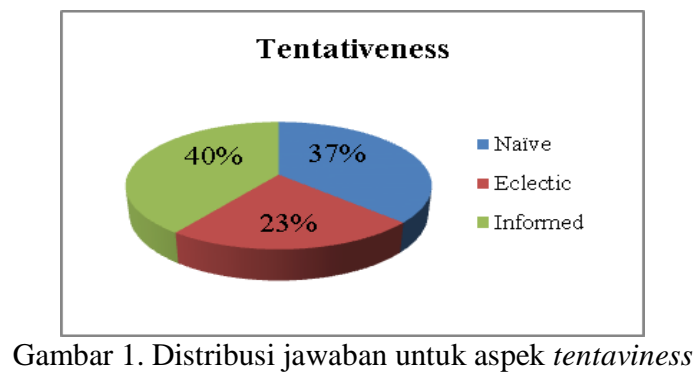

Sebanyak $40 \%$ calon guru kimia telah memiliki pandangan yang benar, dimana pandangan mereka yang menyatakan bahwa teori dapat berubah seiring dengan perkembangan ilmu pengetahuan dan teknologi. Selain menjelaskan pandangan tersebut calon guru kimia juga mampu menyebutkan contoh perubahan atas suatu teori, seperti teori atom Dalton yang kemudian disempurnakan oleh ilmuwan berikutnya seperti Thomson, Rutherford, maupun Bohr. Pendapat ini seiring dengan pendapat ahli pada saat Forum Group Discussion (FGD), yaitu :

Teori-teori sains selalu berubah dan berkembang. (a) Karena teori sains mengikuti perkembangan ilmu pengetahuan dan teknologi. Perkembangan teori-teori ilmiah senantiasa mengalami perubahan menyesuaikan dengan hasil penemuan yang baru atau bukti bukti ilmiah terbaru. (b) Secara basic nya, teori relatif tak mengalami perubahan, akan tetapi secara substantif mengalami penyempurnaan, sehingga konsep tentang atom makin jelas, lengkap dan detail. Dengan perubahan tersebut teori yang dihasilkan semakin kuat, semakin kuat pula kedudukannya dalam ilmu pengetahuan. Contoh pada teori atom, awalnya, atom terdiri dari proton dan elektron yang tersebar merata pada permukaanya. Pada perkembangan ilmu selanjutnya, ternyata proton dan elektron ditengah, sementara elektron mengelilingi dengan aturan aturan tertentu.

Meskipun kategori jawaban calon guru kimia didominasi pada kategori informed, namun jumlahnya hampir berimbang dengan kategori naïve yaitu 37\%. Hal unik yang ditemukan pada jawaban kategori naïve baik dari jawaban kuisioner maupun wawancara adalah siswa menyadari bahwa ada perkembangan dari model-model atom, mulai dari atom Dalton hingga model atom modern. Namun, calon guru kimia tersebut tidak memahami bahwa teori itu dapat berubah seiring dengan penemuan terbaru. Dari hasil wawancara, tersirat bahwa ketika teori atom Dalton atau teori atom Thomson masih dipelajari, maka mereka menganggap bahwa teori tersebut benar dan masih dipakai hingga sekarang. Hal ini dapat diakibatkan karena kurang kritisnya cara berpikir siswa (Wilujeng, Kun, \& Suryadarma, 2017). Seorang calon pendidik harus menyadari sifat tentatif sebuah ilmu pengetahuan, agar tidak salah memberikan pemahaman kepada calon siswanya.

\section{Aspek Empirical basis}

Aspek empirical basis tergambar pada pertanyaan kedua pada kuisioner. Pada aspek ini menunjukkan bahwa sains memiliki ketergantungan pada data dan bukti empiris, berbeda dengan fokus seni pada estetika atau kepercayaan agama pada iman dan kebenaran yang diungkapkan. Meskipun para ilmuwan cenderung melihat bukti empiris sebagai pendukung utama, tetapi hal ini tidak membuktikan dalam arti absolut (Schwartz \& Lederman, 2008).

Pertanyaan kuisioner kedua mengenai kepastian teori yang disampaikan oleh ilmuwan. Ketika ilmuwan menyatakan atom merupakan inti pusat yang terdiri dari partikel bermuatan positif (proton) dan partikel netral (neutron) dengan partikel bermuatan negatif (elektron) yang mengorbit terhadap inti, maka diminta 
pandangan calon guru kimia akan kepastian teori tersebut.

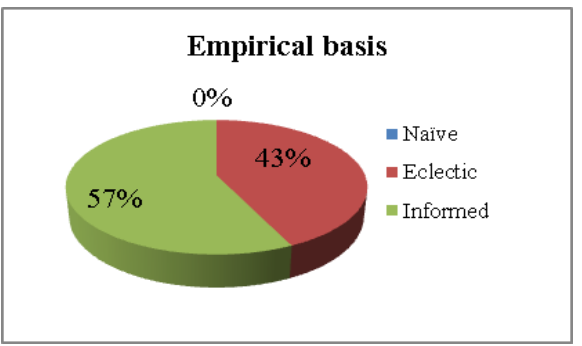

Gambar 2. Distribusi jawaban kategori empirical basis

Sebanyak $57 \%$ calon guru kimia memiliki pandangan bahwa teori yang disebutkan adalah pasti, karena teori tersebut lahir dari hasil eksperimen Rutherford yang belum ada yang menyangkal hal tersebut setelahnya. Pendapat ini lahir dari pandangan yang sesuai dengan NOS. Dan dari hasil kuisioner tidak ada jawaban calon guru kimia yang masuk pada kategori naïve, melainkan semua jawaban tersebar hampir merata pada kategori eclectic dan informed sebesar $43 \%$ dan $57 \%$. Hal ini berarti bahwa semua calon guru sudah memiliki pandangan yang benar terhadap NOS terhadap aspek empirical basis. Adapun pandangan ahli mengenai aspek ini, sebagai berikut:

Sampai saat ini, ilmuwan yakin dengan teori tersebut, sampai nanti ditemukan teori terbaru yang dapat membantah teori lama. Para ilmuan menyakini struktur atom tersebut didasarkan hasil percobaan Rutherford dengan penembakan partikel alpha pada lempeng tipis emas. Rutherford menyimpulkan bahwa dalam atom yang sebagian besar merupakan ruang kosong terdapat inti yang padat pejal dan masif bermuatan positif yang disebut sebagai inti atom; dan elektron-elektron bermuatan negatif yang mengitari inti atom. Bukti lain bisa digunakan jumlah massa atom dan nomor atom yang menunjukkan adanya renik neutron pada inti disamping proton. Adanya elektron dengan jumlah tertentu dapat juga dibuktikan melalui reaksi-reaksi yang melibatkan elektron valensi dan ini bisa dijelaskan juga menggunakan tabel periodik unsur dan teori-teori pendukungnya.

Dari 6 aspek NOS, aspek empirical basis adalah satu-satunya aspek yang tidak ada satupun pandangan calon guru kimia masuk kategori naïve. Hal ini menunjukkan bahwa aspek empirical basis sudah disadari dan dipahami oleh semua calon guru kimia. Hal ini dikarenakan faktor eksperimen dan data percobaan adalah identitas sains dan ilmuwan (Schwartz \& Lederman, 2008). Jadi, calon guru kimia tidak asing lagi mengenai aspek empirical basis.

\section{Aspek Theories and laws}

Pada aspek ini ditekankan bahwa pengetahuan ilmiah dapat berupa hukum atau berupa teori. Pada pertanyaan ketiga pada kuisioner ini diminta calon guru kimia membedakan teori ilmiah dengan hukum ilmiah beserta contoh yang dapat mengilustrasikannya. Dari hasil kuisioner terlihat bahwa jawaban didominasi kategori eclectic sebanyak $47 \%$. Untuk kategori informed sebanyak $40 \%$ dan kategori naüve sebanyak 13\%. Hasil ini juga seiring dengan penemuan Lokollo, Hernani, \& Mudzakir (2019) bahwa responden telah memiliki pandangan yang realistis terhadap aspek teori dan hukum dalam konsep hakikat sains.

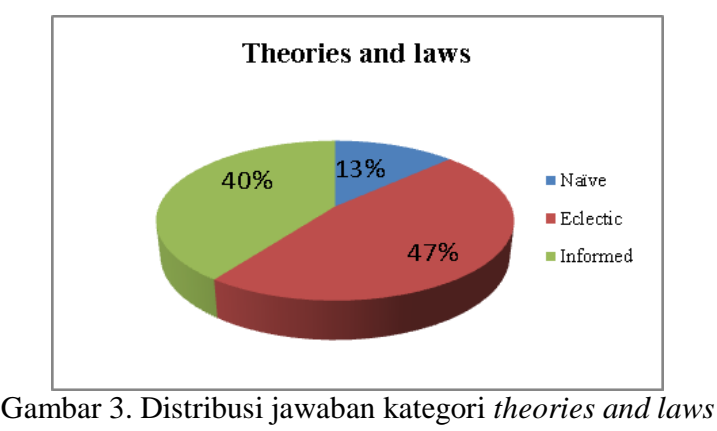

Hal ini berarti bahwa pada umumnya calon guru kimia sudah memiliki pandangan NOS yang tepat untuk aspek theories and laws. Namun baru sebagian yang mampu menjelaskan dengan tepat beserta menyertakan contoh sebagai penjelasan. Dari hasil wawancara ditemukan alasan mengapa mereka mampu membedakan antara teori dan hukum yatu dikarenakan di dalam pembelajaran kimia ditemukan pembahasan mengenai teori-teori dan hukum hukum dalam kimia.

Adapun pandangan ahli terhadap aspek theories and laws pada pertanyaan kuisioner ketiga ini adalah sebagai berikut :

Ya, terdapat perbedaan antara teori ilmiah dan hukum ilmiah. Hukum ilmiah menjelaskan terjadinya suatu fenomena, sedangkan teori menjelaskan mengapa fenomena itu bisa terjadi. Contoh hukum kekekalan massa bisa menjelaskan fenomena tidak berubahnya total massa sebelum dan setelah reaksi tetapi tidak bisa menjelaskan mengapa massanya tetap. Ini dijelaskan oleh teoriteori kimia seperti teori valensi dan lainnya. Teori merupakan pandangan atau gagasan ilmuwan. Teori adalah pandangan yang masih bersifat umum dan belum bisa diperiksa kebenarannya secara empiris. Contoh dalam film startrex, dulu, beberapa puluh tahun lalu orang punya gagasan dapat berbicara dengan lawan bicara dan melihatnya. Kalau kita lihat film-film kartun 
zaman dahulu, seperti mutahil waktu itu. Para ilmuwan hanya memiliki teori pada waktu itu, sekarang, dapat terbukti dengan adanya video call mengunakan smartphone. Contoh lain, teori fisi untuk bom nuklir juga baru diujicobakan puluhan tahun setelah dikemukakan oleh ilmuwan Albert Einstein.

Pada kategori jawaban naïve, sebanyak $13 \%$ calon guru kimia menganggap bahwa teori dapat berubah menjadi hukum jika didukung oleh bukti-bukti ilmiah yang ada. Selain itu, yang salah juga mengenai pandangan bahwa hukum memiliki status lebih tinggi daripada teori. Padahal teori dan hukum merupakan pengetahuan yang berbeda dan yang satu tidak menjadi yang lain. Teori dan hukum sama kedudukannya dengan produk sains (Lederman et al., 2002).

\section{Aspek Creativity}

Aspek creativity terdapat pada pertanyaan kuisioner keempat dan kelima. Pertanyaan keempat meminta pandangan responden atas perbedaan dan persamaan antara sains dengan seni. Dan kemudian pertanyaan kelima melanjutkan permintaan pandangan atas keterlibatan kreativitas oleh para ilmuwan dalam melakukan eksperimen.

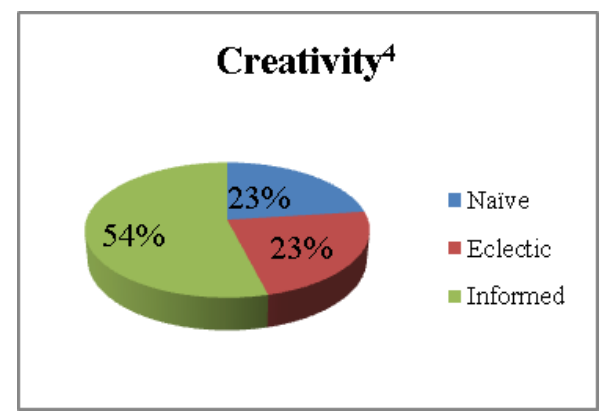

Gambar 4. Distribusi jawaban kategori ceativity pertama

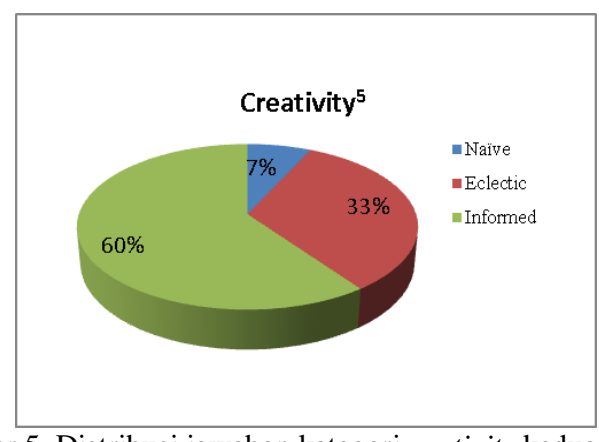

Gambar 5. Distribusi jawaban kategori ceativity kedua

Dari hasil kuisioner, jawaban didominasi oleh kategori informed, pada jawaban kuisioner keempat dan kelima adalah $54 \%$ dan $60 \%$. Sangat sedikit yang kategori jawabannya naïve, hanya $23 \%$ dan $7 \%$. Artinya calon guru kimia telah memiliki pandangan NOS yang cukup mengenai aspek creativity.

Adapun pandangan ahli terhadap pertanyaan kuisioner keempat ini akan menunjukkan pemahaman terhadap aspek creativity, yaitu :

Sains dan seni sama-sama berperan penting dalam membentuk peradaban, mengasah daya kreativitas, kemampuan analisis dan sintesis. Keduanya berlandaskan proses yang sama, yaitu pengembangan daya, kreatifitas, imajinasi, dan kemampuan sintesis. Walaupun karya yang dihasilkan berbeda, daya kreatif seorang saintis menerjemahkan konsep alam sama halnya dengan seorang seniman yang menghasilkan lukisan ataupun lagu. Perbedaannya adalah pada jenis produk karya yg dihasilkan oleh sains dan seni. Daya kreatif seorang saintis menerjemahkan konsep alam menghasilkan karya berupa teori dan hukum sains, dan seorang seniman yang menghasilkan karya lukisan, lagu, ataupun novel.

Selanjutnya pandangan ahli terhadap pertanyaan kuisioner kelima adalah sebagai berikut :

Ya, dalam proses pembuktian hipotesis dan pencarian kebenaran, seorang saintis disamping menyusun rencana dan menggunakan metode ilmiah juga menggunakan daya kreatif, imajinasi dan analisis dan sintesisnya. Imajinasi berguna untuk meramalkan, menata ulang suatu teori untuk dibuktikan kebenarannya secara empiris. Kreativitas dan imajinasi diperlukan dalam melakukan pemecahan masalah dalam konteks di dunia nyata. Contoh saja, mungkin banyak orang yang sering kejatuhan buah kecil dari pohon ketika ada di bawahnya, tetapi hanya Newton yang memikirkannya dan dapat menggunakannya menjadi dasar teori gravitasi. Suatu ketika Jabir Ibnu Hayyan tidak sengaja menumpahkan larutan cuka ke dalam ember, berisi air. Beliau berimajinasi bagaimana memisahkan kembali cuka dari air tersebut. Muncullah ide melakukan proses destilasi.

Sains menyangkut penemuan dari penjelasan dari teori yang ada, dimana membutuhkan kreativitas dalam diri ilmuwan. Dalam penyelidikannya, ilmuwan menggunakan kreativitas dan imajinasinya (Lederman et al., 2002). Tanpa imajinasi, ilmuwan tidak dapat berkreasi membuat suatu rangkaian percobaan atau pengamatan untuk mengamati fenomena alam. Oleh karena itu, kreativitas dan imajinasi sangat penting dalam sains. Dari hasil kuisioner terlihat bahwa para calon guru kimia cukup memahami keterkaitan antara sains dengan kreativitas. 


\section{Aspek Subjectivity, dan}

\section{Aspek Social/ cultural embeddedness}

Pada aspek subjectivity ditekankan bahwa subyektivitas pribadi ilmuwan tidak dapat terhindarkan dalam ilmu pengetahuan ilmiah. Salah satunya adalah para astronom memiliki perbedaan pendapat yang saling bertolak belakang tentang nasib akhir alam semesta. Ilmu akan dipengaruhi oleh teori dan hukum ilmiah yang berkembang saat itu. Pengembangan eksperimen atau interpretasi data akan disaring melalui kacamata teori yang sedang berlaku. Ini adalah subjektivitas tidak dapat dihindari (Abdel-khalick, Bell, \& Lederman, 1997).

Selanjutnya aspek social/ cultural embeddedness memiliki dua makna, yaitu budaya terhadap sains itu sendiri, dan budaya yang ada dimasyarakat. Pertama, budaya sains itu sendiri terkait aturan-aturan yang melekat dalam eksperimen, pengumpulan dan penafsiran data. Hal ini menjadi pengendali dari subjektifitas ilmuwan. Kedua, sains dipengaruhi oleh faktor-faktor sosial, seperti politik, ekonomi dan agama. Seperti contoh teori evolusi yang tidak diterima di Perancis namun didukung di Jerman untuk elemen nasional, sosial, dan juga budaya (Lederman et al., 2002).

Aspek Subjectivity, dan social/ cultural embeddedness terdapat pada pertanyaan keenam kuisioner. Pertanyaannya mengenai perbedaan kesimpulan yang terjadi pada ilmuwan terhadap peristiwa nasib akhir alam semesta, dimana ada dua kesimpulan yang berbeda, yaitu alam semesta mengalami perluasan, dan alam semesta mengalami penyusutan, padahal ilmuwan melihat eksperimen dan data yang sama.

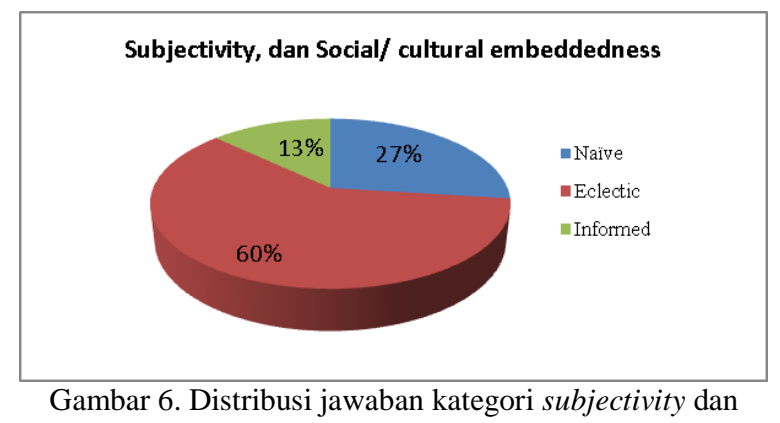
social embeddedness

Dari jawaban kuisioner yang didapat, masih sedikit jawaban mereka yang masuk pada kategori informed, yaitu 13\%. Sedangkan persentase terbanyak ada pada kategori eclectic yaitu $60 \%$, sedangkan kategori naïve masih terdapat $27 \%$. Penemuan ini seiring dengan hasil penelitian Adiputra, Mudzakir, \& Widhiyanti,
(2019) yang menyatakan bahwa pandangan responden terhadap NOS masih pada level 2 dari 3 level yang dikategorikan. Hal ini berarti bahwa calon guru kimia telah memiliki pandangan yang tepat terhadap NOS, namun belum mampu memberikan penjelasan. Data ini menunjukkan bahwa dibutuhkan penanaman aspek NOS di dalam pembelajaran atau di dalam kurikulum agar pemahaman dan tujuan pendidikan sains tercapai (Prachagool \& Nuangchalerm, 2019).

Adapun pandangan ahli mengenai aspek subjectivity, dan social/ cultural embeddedness, sebagai berikut:

Perbedaan itu terjadi disebabkan oleh teoriteori yg digunakan sebagai dasar. Saintis yang menyatakan alam ini dinamis dan mengembang didasarkan pada teori Big Bang. Bukti teori Big Bang adalah adanya temuan objek di alam semesta semakin menjauh. Hal ini menandakan adanya pengembangan dari suatu titik dimasa lalu. Sedangkan saintis yang mengatakan alam ini statis didasarkan pada teori steady state yg mengatakan bahwa alam ini menjaga kepadatan rata-rata secara konstan. Menurut teori ini alam semesta tak ada awal dan tak ada akhirnya. Teori-teori tentang alam semesta ini sulit diverifikasi karena waktunya sudah sangat panjang. Adanya pengamatan terhadap data yang sama, tetapi menghasilkan kesimpulan yang berbeda, bisa terjadi karena: (i) kesalahan pengambilan kesimpulan dari pengamatan eksperimen; atau (ii) adanya subjektivitas dari pengamat terhadap data hasil eksperimen tersebut.

Dari hasil wawancara juga didapat pernyataan calon guru kimia bahwa mereka tidak bisa menjelaskan karena bidang astronomi bukan bidang keilmuan mereka. Atau maksudnya di luar bidang kimia. Namun, aspek subjectivity, dan social/ cultural embeddedness adalah aspek yang perlu dipahami oleh seorang calon guru kimia. Dimana, pengetahuan ilmiah juga tidak lepas dari subjektifitas pribadi penelitinya dan pengaruh lingkungan sosialnya. Sehingga, perlu disadari bahwa dari eksperimen dan data yang sama, bisa terjadi kemungkinan penterjemahan yang berbeda antar peneliti.

\section{KESIMPULAN}

Hasil penelitian menunjukkan bahwa calon guru kimia telah memiliki pandangan yang cukup memadai tentang Nature of Science. Dari 6 aspek NOS tersebut, 4 aspek diantaranya telah terkategori informed, sedangkan 2 aspek lainnya masuk kategori eclectic. Dan tidak ada kategori jawaban naïve yang mendominasi jawaban calon guru kimia. Implikasi hasil penelitian ini akan 
dijadikan sebagai dasar acuan penelitian lanjutan mengenai konstruksi desain pembelajaran yang bermuatan Nature Of Science bagi calon guru kimia.

\section{UCAPAN TERIMAKASIH}

Terima kasih penulis ucapkan kepada Direktorat Riset dan Pengabdian kepada Masyarakat (DRPM), Direktorat Jenderal Penguatan Riset dan Pengembangan, Kementerian Riset, Teknologi, dan Pendidikan Tinggi anggaran 2019 yang telah mendanai penelitian ini.

\section{DAFTAR RUJUKAN}

Abd-el-khalick, F., \& Akerson, V. L. (2009). The Influence of Metacognitive Training on Preservice Elementary Teachers' Conceptions of Nature of science. International Journal of Science Education, 31(16), 2161-2184. https://doi.org/10.1080/095006908025633 24

Abd-el-khalick, F., Bell, R. L., \& Lederman, N. G. (1997). The Nature of Science and Instructional Practice : Making the Unnatural Natural. John Wiley \& Sons, Inc.

Adiputra, I. G. E. D., Mudzakir, A., \& Widhiyanti, T. (2019). How do the preservice chemistry teachers view about the nature of science and technology? In Journal of Physics: Conference Series. IOP Publishing. https://doi.org/10.1088/17426596/1157/4/042043

Ağlarcı, O., Sarıçayır, H., \& Şahin, M. (2016). Nature of science instruction to Turkish prospective chemistry teachers: The effect of explicit-reflective approach. Cogent Education, 3, 1-19. https://doi.org/10.1080/2331186X.2016.12 13350

Akerson, V., \& Donnelly, L. A. (2009). Teaching Nature of Science to K - 2 Students : What understandings can they attain? International Journal of Science Education, 32(1), 97-124. https://doi.org/10.1080/095006909027172 83

Akerson, V. L., Abd-el-khalick, F., \& Lederman, N. G. (2000). Influence of a Reflective Explicit Activity-Based Approach on Elementary Teachers, Conceptions of Nature of Science. Journal Of Reseach In Science Teaching, 37(4), 295-317.
Asikin, N., \& Yulita, I. (2019). Scientific Literacy-Based Chemical Teaching Materials Design of Chemical Solution Materials on Sea Pollution Context. Jurnal Penelitian Pendidikan IPA, 5(2), 204-211. https://doi.org/10.29303/jppipa.v5i2.249

Holbrook, J. (2005). Making Chemistry Teaching Relevant. Chemical Education International, 6(1), 1-12.

Lederman, N. G., Abd-el-khalick, F., Bell, R. L., \& Schwartz, R. S. (2002). Views of Nature of Science Questionnaire : Toward Valid and Meaningful Assessment of Learners ' Conceptions of Nature of Science. Journal Of Research In Science Teaching, 39(6), 497-521. https://doi.org/10.1002/tea.10034

Lokollo, L., Hernani, H., \& Mudzakir, A. (2019). Pre-service chemistry teacher' s view about the nature of science and technology. In Journal of Physics: Conference Series 1157. IOP Publishing. https://doi.org/10.1088/17426596/1157/4/042036

McComas, W. F. (2002). The nature of Science in Science Education Rationales and Strategies. Kluwer Academic Publishers.

McComas, W. F., \& Almazroa, H. (1998). The Nature Of Science in Science education: An Introduction. Science \& Education, 7, 511-532.

Nentwig, P. M., \& Demuth, R. (2007). Chemie im Kontext : Situating Learning in Relevant Contexts while Systematically Developing Basic Chemical Concepts, 84(9), 1439-1444.

Prachagool, V., \& Nuangchalerm, P. (2019). Investigating The Nature Of Science: An Empirical Report On The Teacher Development Program In Thailand. Jurnal Pendidikan IPA Indonesia, 8(1), 32-38. https://doi.org/10.15294/jpii.v8i1.17275

Schwartz, R., \& Lederman, N. (2008). What Scientists Say: Scientists 'views of nature of science and relation to science context. International Journal of Science Education, 30, 727-771. https://doi.org/10.1080/095006907012258 01

Sugiyono. (2012). Metode Penelitian Kuantitatif Kualitatif dan $R \& D$.

Wilujeng, I., Kun, Z. P., \& Suryadarma, I. G. P. (2017). Science learning based on local potential : Overview of the nature of science ( NoS ) achieved. In AIP Conference Proceedings 1868, 080005 (pp. 
72 | Jurnal Zarah, Vol. 7 No. 2 (2019)

1-7). AIP Publishing.

https://doi.org/10.1063/1.4995189
Yulita, I. (2018). Analisis Prekonsepsi Siswa Terhadap Kemampuan Menghubungkan Konteks Air Laut Dengan Konten Hakikat Ilmu Kimia Kelas X SMA. Jurnal Pendidikan Sains, 6(1), 64-72. 
Lampiran A

\section{KUESIONER VNOS FORM B}

\section{PETUNJUK PENGISIAN :}

Jawablah pertanyaan-pertanyaan berikut ini, silakan gunakan halaman belakang jika Anda memerlukannya. Tidak ada jawaban "benar" ataupun "salah" untuk pertanyaan-pertanyaan tersebut. Kuesioner ini hanya untuk memperoleh pandangan Anda terhadap beberapa isu sains.

1. Setelah para ilmuwan menghasilkan sebuah teori (misalnya, teori atom, teori molekul kinetik, teori sel), apakah teori tersebut pernah berubah? Jika Anda percaya bahwa teori-teori tersebut tidak berubah, jelaskan mengapa dan pertahankan jawaban Anda dengan menyertakan contoh. Dan, jika Anda percaya sebaliknya, bahwa teori-teori tersebut berubah, maka : (a) Jelaskan mengapa, dan (b) jika demikian mengapa kita harus repot-repot mengajar dan belajar teori-teori ilmiah?

2. Buku-buku sains kerap memaparkan bahwa atom merupakan inti pusat yang terdiri dari partikel bermuatan positif (proton) dan partikel netral (neutron) dengan partikel bermuatan negatif (elektron) yang mengorbit terhadap inti. Menurut Anda, seberapa pasti ilmuwan mengenai struktur atom tersebut? Apa bukti spesifik yang digunakan para ilmuwan untuk menentukan struktur atom?

3. Menurut Anda, apakah ada perbedaan antara teori ilmiah dan hukum ilmiah? Berikan contoh untuk mengilustrasikan jawaban Anda.

4. Menurut Anda, bagaimana sains dan seni dikatakan serupa? Dan bagaimana juga mereka dikatakan berbeda?

5. Ilmuwan melakukan eksperimen/investigasi ketika mencoba menyelesaikan masalah. Selain dari tahap perencanaan dan desain, apakah para ilmuwan menggunakan kreativitas dan imajinasi mereka dalam proses melakukan eksperimen / penyelidikan ini? Mohon jelaskan jawaban Anda dan berikan contoh yang sesuai.

Baru-baru ini, para astronom memiliki perbedaan pendapat yang mencolok tentang nasib akhir alam semesta. Beberapa astronom percaya alam semesta mengalami perluasan, sementara yang lain, percaya bahwa alam semesta ini menyusut, dan ada pula yang percaya bahwa alam semesta tetap dalam keadaan statis tanpa perluasan ataupun penyusutan. Menurut Anda, bagaimana kesimpulan yang berbeda ini bisa terjadi, jika semua astronom melihat eksperimen dan data yang sama? 
